\title{
Notas a las Notas a las Notas... A Propósito de Manuel Puig
}

\author{
La beterogeneidad de las escrituras \\ es la escritura misma, el injerto. \\ Jacques Derrida, La Dissémination.
}

Critique 262

Con Boquitas Pintadas de Manuel Puig la novela en español delimita un sector preciso de su trayectoria: ese en que un género se vuelve sobre sí mismo, distancia su objeto y lo circunscribe, se aleja de su imagen y la señala, revela, sin abandonarla, pero minándola de suave risa, la densidad de sus convenciones, las redes de su gramática. El escritor renuncia aquí a su orfebrería, a sus tatuajes, a las escenografías que consideraba apenas sugerentes y que ahora le parecen de un lirismo neblinoso y grosero; va a trabajar al revés, dando a leer en lo blanco la figura, en la figura el fondo que en el anverso la sustenta, en las letras lo vacio, en la página lo acuñado por la tinta; se nos despliega la trama, el tejido, el texto como imbricación de hilos (de sentido) y nudos; aquí el que cons. truye al revés, el tapicero, discretamente burlón, complaciente, muestra los bocetos, el andamiaje, los trucos: aquí se trata del "arte" de narrar.

Esta distancia, esta mise en cause de la representación narrativa, inseparable quizá de un cierto humor, tiene un precedente. Pero la cantera de donde los Seis problemas para don Isidro Parodi extrae sus topoi, sus situaciones codificadas - la novela policíaca- permanece siempre como un espacio alógeno, como un sitio precedente y exterior al relato. Antes y fuera de Parodi, de su encierro - también físico- se extiende el ámbito de lo detectivesco, convertido aquí en teatro macarrónico. Como Cervantes, Borges supone un corpus conocido, asimilado por el pensamiento común del momento - situaciones caballerescas o policíacas-, del cual la novela es la reiteración elogiosa y burlesca. La cantera, el ámbito mediato y sobreentendido de Boquitas pintadas es la novela sentimental, el folletín. Pero en la medida en que la entrega -en los dos 
sentidos de la palabra: tan importante es aquí la periodicidad de los cuadernos como la rendición de los cuerpos-, las trabazones epistolares, el énfasis y el suspenso definen no un tipo de novela, sino el nacimiento y constitución del relato popular, de la "ficción" al estado puro, fijando las premisas de la narración pequeño burguesa, en esa medida podemos afirmat que la verdadera cantera del libro es el arte de narrar tal y como nuestras convenciones lo conciben hoy.

Los capítulos no serían "frescos" que enumeraran los lugares comunes del arte plástico - "cromos", clichés, postales, imágenes publicitarias o tiras cómicas - sino paneles en los cuales el agrandamiento o la ambigüedad de la presentación, vaciándolos de todo contenido, conferían igual categoría y majestad a un Cristo bizantino que a una botella de Coca-Cola. No se revelan lugares comunes, sino la sintaxis que ha dado lugar a la ficción en tanto que lugar común. Sus mecanismos son utilizados, pero al vacio: si el artificio policíaco del suspenso consiste en fijar las acciones de los personajes segundo por segundo, en hacer del tiempo dilatado el soporte del terror, Puig va a emplearlo del modo más explícito, pero como vehículo de contenidos a tal punto anodinos que el artificio termina señalándose a sí mismo, aparato inútil cuya única función es la ostentación de su engranaje, la expresión de su juego - gesto lúdico y también articulación de las pieżas de un conjunto-, el espectáculo: "A las 8:30 salió de su casa. Vestía uniforme de algodón azul abotonado adelante, con cuello redondo y mangas largas. $A$ las 8:42 entró en la tienda "Al barato argentino". A las 8:45 estaba en su puesto detrás de la mesa de empaquetar, junto a la cajera y su caja registradora. Los demás empleados, veintisiete en total, también se dispusieron a ordenar sus puestos de trabajo. A las 9 horas se abrieron las puertas al público. La empaquetadora compuso su primer paquete a las 9:15, una docena y media de botones para traje de hombres", etc.

No se trata pues de un libro pop -excepto en el sentido en que lo practica Roy Lichtenstein en quien los contenidos, prácticamente nulos, son menos importantes que el señalamiento de los medios de difusión que utilizamos para transmitirlos-, ni de un objeto camp, ni de un texto tautológico, sino de un archivo, de una arqueología de lo novelesco, de una parodia ${ }^{1}$ de la novela.

1 Parodia, en el sentido preciso que en 1929 definía Backtine: derivada del género "serio-cómico" antiguo, el cual se relacionaba con el folklore carnavalesco - de allí su mezcla de desenfado y tradición-, la parodia utiliza el habla contemporánea con seriedad, pero también 
inventa libremente, juega con una pluralidad de tonos, es decir, habla del habla. Substrato y fundamento de este género - cuyos grandes momentos han sido el diálogo socrático y la sátira menipea--, el carnaval, espectáculo simbólico y sincrético en que reina lo "anormal", en que se multiplican las confusiones y profanaciones, la excentricidad y la ambivalencia, y caya acción central es una coronación paródica, es decir, una apoteosis que es a la vez una irrisión. Las saturnales, las mascaradas del siglo XVI, el Satiricón, Boecio, los Misterios, Rabelais, pero por supuesto y sobre todo el Quijote: éstos son los ejemplos que cita Backtine, señalando como un trazo específico de la parodia la mezcla de géneros, la intrusión, el injerto de un tipo de discurso en otro, ${ }^{1} l_{a}$ abolición de la autonomia narrativa, epistolar, crítica, etc. Backtine subraya que lo importante es que, del modelo de base - que podemos llamar, utilizando la denominación de Julia Kristeva, paragrama-, la obra paródica es a la vez una apoteosis y una irrisión. A la vez que un folletín, casi perfectamente conforme al género. Boquitas pintsedas es la transgresión paródica, el doble irrisorio del folletín.

\section{${ }^{1}$ Coronel Vallejos}

\section{TEATRO LIRICO DE MUÑECAS}

\section{Función única:}

25 de febrero de 1937

9 P. M.

El TELóN - Faisanes del cielo de invierno, hexagramas negros, tigres cubiertos de cuños de lacre rojo - SE ABRE, LENTO. APLAUSOS.

Sudorosos e inmóviles, los portavoces están sentados tras pequeños atriles donde ha sido desplegada la escritura que vocalizan; cuando vuelven una página del libreto, los caracteres verticales se perciben de lejos. Un triángulo de tela rígida, fijado a sus hombros como un barrilete, enmarca los rostros, esos rotros librados a todas las angustias de la voz.

Cobra aparece en escena, y a su alrededor, a la vez visibles e impasibles, se apresuran hombres vestidos de negro, pero sin ninguna afectación de habilidad o de discreción y, si puede decirse, sin ninguna demagogia publicitaria; silenciosos, rápidos, elegantes, sus actos son eminentemente transitivos, operatorios, coloreados por esa mezcla de fuerza y sutileza que caracteriza al vestuario japonés y que es como la eavoltura estética de la eficacia. 
Movida por esos hömbres que la sostienen y acompañan Cobra se acerca. Uno de ellos, el que sostiene sobre el brazo derecho la parte alta de su cuerpo, tiene el rostro descubierto, liso, claro, impertérrito, "como una cebolla blanca recién lavada"; los ayudantes vienen de negro, uno, con guantes pero con el pulgar descubierto, enarbola una gran tijera de hilos con los cuales le mueve el brazo y la mano izquierdos; el otro, arrastrándose, le sostiene el cuerpo, la hace caminar.

En brazos de sus portadores, Cobra avanza hasta el proscenio. Puntúan sus pasos, con grandes golpes de plectro, los tocadores de shamisén. Falbalás de perla, de jade $\mathrm{y}$ de zafiro dividen regularmente su vestido de brocados de oro; le ciñe el talle una faja estrecha que ornan los colores $\mathrm{y}$ los signos del zodíaco. Lleva botines altos, uno negro, cubierto de estrellas de plata, con una luna en cuarto creciente, el otro blanco, con gotas de oro y un sol en medio. Sus mangas amplísimas -esmeraldas y plumas de pájaros- dejan ver los brazos; en sus puños" se entoscan brazaletes de ébano; las manos, cargadas de sortijas, terminan en uñas tan afiladas que las puntas de sus dedos parecen agujas. Una cadena de oro macizo, pasándole bajo el mentón, sube a lo largo de sus mejillas y se enrosca en espiral en sus cabellos cubiertos de un polvo anaranjado, luego, descendiendo, le roza los hombros y termina en su pecho, atando un escorpión de diamante cuya lengua se introduce entre sus senos. Dos grandes perlas rubias le alargan las orejas. Para protegerla del resplandor de las candilejas superiores, una mucama obesa y harapienta despliega un parasol verde; cascabeles bermellón tintilan alrededor del mango de marfil. Doce negritos rizados llevan la cola de su vestido, cuyo extremo, a cada rato, levanta un monito.

Cobrá está maquillada con violencia, la boca de ramajes pintada. Las órbitas son negras y plateadas de alúmina, estrechas entre las cejas y luego prolongadas por otras volutas, pintura y metal pulverizados, hasta las sienes, hasta la base de la nariz, en anchas orlas y arabescos como de ojos de cisne, pero de colores más ricos y matizados; del borde de los párpados penden no cejas sino franjas de ínfimas piedras preciosas. Desde los pies hasta el cuello parece mujer, arriba su cuerpo se transforma en una especie de animal heráldico de hocico barroco. En la voz de los recitantes vienen a unirse: la declamación exagerada, el trémolo, el tono sobreagudo, femenino, las entonaciones rotas, los llantos, los paroxismos de la cólera, de la queja, de la súplica, del asombro, el pathos indecente, toda la cocina de la emoción elaborada manifiestamente al nivel de ese cuerpo interno, visceral, cuyo músculo de expresión es la laringe. 
Sobre ese fondo desgarrado el canto de Cobra se eleva, sin oscilaciones, casi monocorde, grave.

La Nené (A MABEL) - -Vos me dirás lo que quieras, pero yo la encuentro un poco... cargada.

Mabel. - ... y con esa voz tan gruesa... yo encuentro que una mujer, ante todo, debe ser natural... nunca afectada. Bueno, la moda en París debe ser así...

La Raba (PARA sí misMA).- Si ella, con esos pies tan enormes, ha llegado. a ser reina del Teatro Lírico de Muñecas, dónde no llegaré yo con. los míos... pero mejor no digo nada. Una criada es siempre una: criada.

Los tocadores de shamisén, a un signo, se detienen.

Muros de papel blanco se deslizan ante ellos.

Los recitantes callan.

Sin levantar los pies, como si fuera resbalando sobre el piso, Cobra: se retira.

\section{TELON}

\section{Aplausos}

Un hombrecillo color mostaza, casi enteramente cubierto con un capuchón negro, aparece en el proscenio y declama:

Los decorados del Teatro Lírico de Mulñecas son de Roland Barthes. (APLAUSOS FRENÉTrCOS) y fueron realizados para su Lección de Escritura, en Tel Quel 34... La frase "como una cebolla blanca recién lavada" pertenece a un haikú de Bashô:

"una cebolla blanca
recién lavada:
impresión de frío".

El traje de Cobra es de Gustave Flaubert (1821-1880) y fue estrenado por la reina de Saba en Las Tentaciones de San Antonio.

El maquillaje, de Giancarlo Marmori (Aplausos), es el de Vous en Storia de Vous o Cérémonie d'un Corps.

La Nené, Mabel y la Raba son las tres mujeres de Boquitas Pintadas, de Manuel Puig (Aplausos, gritos de "¡Viva la Patria!", etc.). 


\section{EL TELON VUELVE A ABRIRSE. LAS MUNECAS VAN A SALIR PARA EL SALUDO FINAL}

\section{¿Cuál era en ese momento el mayor deseo de Cobra?}

En ese momento su mayor deseo era ser aclamada en Coronel Vallejos. ¿Cuál era en ese momento su temor más grande?

En ese momento su temor más grande era que se le cayera la peluca color zanahoria rayada (sí, con rayas cobrizas) que la mamarracha de la Cadillac le había encasquetado como pudo, a última hora y borracha como estaba, toda biliosa y humillada por el fracaso de su numerito bailable... verdad es que nada más que a ella se le ocurre montar nada menos que la Cumparsita para una tournée argentina. ${ }^{1}$

1 Es decir, que más que notas en las notas, se trata de injertos: "Así se escribe la cosa. Escribir quiere decir injertar. Es la misma palabra. El decir de la cosa es devuelto a su ser-injertado. El injerto no surge en lo propio de la cosa. No hay más cosa que texto original".

"Todos los extractos textuales que sirven de escanción a Nímeros, la novela de Philippe Sollers, no dan lugar, como usted pudo creerlo, a "citas" o a "collages". Estos no están aplicados en la superficie o en los intersticios de un texto que existiría ya sin ellos. Estos extractos no se leen más que en la operación de su reinscripción, en el injerto. Violencia apoyada y discreta de una incisión inaparente en el espesor del texto, inseminación calculada de lo alógeno en una proliferación gracias a la cual los dos textos se transforman, se deforman uno al otro, se contaminan en sus contenidos, tienden a veces a expulsarse, pasan elípticaimente uno en el otro y se regeneran allí en la repetición, en los bordes del sobrehilado (surjet). ${ }^{1}$ Cada texto injertado continúa irradiando hacia el sitio de su extracción y también lo transforma afectando el nuevo teirreno." Jacques Derrida, La Dissémination.

1 El Crítico (AFLIGIDO).-La literatura, pues, no es más que injerto...

Otro escritor-Para mí... sería un vasto juego de espejos cuyo idiagrama es el de mi propio rostro (CLOSE-UP DEJ. SUSODICHO ROSTRO).

Otro.-Para mí, un testimonio desgarrado y convulso de nuestro siglo, un documento alucinado y alucinante (LE ENTRA UNA TOSECITA BOBA) ... un ... (ZOOM A SUS MANOS: DEDOS NUDO- 
SOS, LARGUIRUCHOS, ENROSCANDOSE UNOS EN OTROS).

Otro-- $\mathrm{L}$ a des-construcción de los sintagmas codificados / todo es lenguaje: / la construcción de una galaxia de sentido cuyo sentido último es otra galaxia / (LA CAMARA SE ENFOCA A SI MISMA ENFOCANDOSE MIENTRAS SE ENFOCA ... Y ASI HASTA LA NAUSEA).

Otro.-Un entretenimiento divino... algo así ... como tejer!1

1 Somos herederos de una literatura cuyo soporte, cuyo substrato último no debe buscarse en ningún sitio fuera del lenguaje, sino al contrario en la ideología subyacente o inscrita en la teoría occidental (al menos) del lenguaje, teoría sometida a la categoría metafísica de la expresividad y a su correspondiente armazón sintáctica, fonética, gráfica, etc. De este lenguaje que permite la comunicación al nivel de la inforción y el cambio al nivel utilitario de los contenidos, de lo transitivo, del fondo (casi en el aspecto bancario del término) ilustra y garantiza el funcionamiento una cierta literatura.

La compostura del discurso, la coherencia sintáctica; la unidad de tono, el sentido de la escritura como fresco, como expresión de una interioridad psicológica, de un yo que la subyuga y anula o de una exterioridad que igualmente la oblitera: todo lo que supone un espacio exterior y precedente a la materialidad del texto (espacio que desde su willeurs lo dirige y organiza, determina y alinea sus signos) participa de la concepción teológica del lenguaje, consolida el funcionamiento de su concepción representativa, las redes de la retórica dominante.

La subversión de esas redes (la de sus inherentes premisas ideológicas) reviste hoy las modalidades menos aparentes, más diversas. Aventuro aquí dos, radicales: en ellas el autor, el sujeto productor de sentido, central, uno (sin fallas), dueño de su discurso, queda significado por una ausencia, señalado por el sitio vacío desde donde el texto se genera. La primera modalidad asume los rasgos de la saturación, la segunda los del vacío.

a) El trabajo en Compacto de Maurice Roche ha tenido lugar al nivel más superficial - después del párrafo anterior no será necesario señalar que doy en este contexto a la palabra superficie una connotación positiva. Aquí lo que se ha labrado, cifrado, es el estrato exterior del lenguaje; la materia gráfica (fonética) del signo ha sido no sólo barajada, permutada, condensada, sino tatuada —obsesión de tatuajes: grafía sobre (en) la piel- hasta convertirla en una substancia hipergráfica, 
aparentemente supersignificante. Pero a fuerza de cargarla - también en el sentido popular de la palabra: hembra embarazada - la materia de la frase estalla; la información se dispersa, contradice o anula: el texto muestra su compacidad -en oposición a lo difuso del lenguaje transitivo- en tanto que instancia del tatuaje. Los códigos más disímiles, desde el sistema Braille hasta el pentagrama, desde los jeroglíficos hasta las fórmulas matemáticas, vienen en Compacto y en Circus (inédito) a alterar, injertándose en ella, la linearidad de la escritura, la progresión de nuestro sistema de lectura —imágenes de un sentido del tiempo-, a desmentir la precedencia de la palabra hablada con relación a la escrita -imagen de un espacio logocéntrico-, de la foné con respecto al grafo, a dar a la página un alcance ideogramático, o paródicamente ideogramático, cuya densidad no deja intersticios a la expresión del autor, página que exalta lo que (se) juega en su superficie, la inscripción de sus cifras.

b) El trabajo realizado en Boquitas Pintadas de Manuel Puig opera en sentido totalmente opuesto: lo que se nos muestra del lenguaje es la vacuidad, lo que en él se subraya es su carácter de vehículo, de medio de transmisión y soporte de ideas recibidas; el de la frase, el volumen que definen las aristas sintácticas es el del lugar común: núcleo mitológico, estampa elaborada, decantada, eidos popular, concreción de fantasmas colectivos, situación codificada: sitio de encuentro.

Aquí la página es una superficie pulida, plana, sin rupturas, en la cual sin matices, nítidos, vienen a reflejarse en la agresividad icónica de sus dibujos esquemáticos y sus colores acrílicos, en la severidad industrial de su multiplicación, las imágenes seriales que el lenguaje transitivo crea y transporta, la substancia informativa sin ambigüedades ni residuos de que son productores y vehículos los sistemas masivos de comunicación.

Pero la diferencia entre Boquitas Pintadas y un folletín canónico es absoluta. Si bien la constitución del libro, por entregas, y su reivindicación de ciertos tópicos del abigarrado "texto" popular, justifican el subtítulo, además de las evidentes disconformidades técnicas -empleo del flash-back, mezcla de géneros, progresión tangencial del relato, ruptura de la linearidad narrativa, empleo del collage, índice paródico, etc.-, hay una, de orden teórico, que atraviesa la materia misma de la obra: en un folletín, en sentido literal, no hay personajes; entre los lugares comunes y los actores que los habitan, entre las entidades nombradas y la estructura que las contiene, no hay vacíos, no hay intersticios, ambos se corresponden idealmente. Los héroes del "sitio de encuentro" no existen más que en la medida en que abrazan las líneas del continente, en que se mimetizan y confunden con él sin dejar tesiduos, sobras. Ya se trate de 
folletín o de "cromo", de imágenes de Epinal o de El Derecbo de Nacer, "de" Félix B. Cagnet, de postales en colores o de novelas "de" Corín Tellado ${ }^{1}$-en estos casos, y en última instancia en todos, la preposición, esa patente de corso de un individuo con relación a un lenguaje que cree producir y que en realidad lo produce, debía abolirse:- el circuito entre el actuante (unidad semántica de la armadura del relato) y el actor (su unidad lexicalizada) es aquí mínimo.

1 "Tenían un piso coquetón, lujoso, moderno. Tres años antes lo habían estrenado ellos. Vicente lo había alquilado para casarse y lo amueblaron a gusto de ambos. Se trataba de un tercer piso en una casa do doce plantas. Era grande y cómodo y estaba situado en una de las principales calles de la capital. No faltaba en él ningún aparato automático. y la criada y la cocinera estaban encantadas, porque en casa de los Mecayo habia muy poco quehacer".

" "Patricia Natalia Acebal (Pat para los amigos y conocidos) se tiró al lecho de muy mal humor. Hacía un dia pésimo y si bien no llovía aún, no tardaria en hacerlo. Y Pat detestaba la lluvia. Era una muchacha de unos veinticuatro años, de pelo rojizo, peinado con arte y elegancia. Tenía los ojos grises, de un gris acerado y frío, pero muy hermosos, y un cuerpo esbelto, si bien frágil, muy femenino".

Corín Tellado, La secretaria de mi marido.

"Sus miradas chocaron y fue tanto el amor que Juan Miguel leyó en los iris de cielo que, sin lograr contenerse, besó con loca vehemencia las pupilas celestes, que ya eran suyas, para siempre suyas. Una y mil veces besó las mejillas arreboladas. Posó con poderío los labios en aquellos otros temblotosos, y de esta forma perdió el dominio sobre sí mismo, llegando, incluso, a asustar a la chiquilla que tan ciegamente confiaba en él.

-Eres mía - susurraba, apasionado. Ya nadie tendrá derechos sobre tí; yo sólo seré tu dueño, muñeca adorada, tu dueño!

-Mike, por favor, sé juicioso.

- ¿Me pides juicio, cuando sólo sé saciar las ansias de ti que con trabajo he venido dominando continuamente? $\mathrm{No}$, mi nena; ya nunca más nos separaremos. Nada me importa ni que seas nieta de Labra ni que fueras modernista. ¡Qué más da! Desde ahora eres solamente algo mío, y nuestras vidas habrán de ir unidas para el resto de nuestra existencia. Ella rió, feliz, acariciando, mimosa, con inefable deleite, la cabeza morena, inclinada hacia él. 
- Si, Mike adorado, seremos el uno para el otro, y nuestras vidas habrán de ser un paraíso en el mar... -concluyó picaruela.

- ¿En el mar?

- ¡Naturalmente! ¿Ignoras acaso -ironizó, apasionada- que navegamos rumbo a Liverpool!?"1

Corin Tellado, Era el amor.

1 Al contrario, la discordancia, el décrocbage entre los personajes y los lugares comunes que orientan y modelan sus vidas son, en los dos volúmenes de que ya se componen las "actas" argentinas de Manuel Puig, máximos. El lugar común desempeña en ellos, textualmente, el papel de la fantasía, en el sentido psicoanalítico del término: producción puramente ilusoria que no resistiría a una aprehensión correcta de la realidad, secuencia imaginaria (pero inimaginable), libreto que en nosotros se escribe y en el que, deformándonos, nos introducimos como tema; ese teatro sin límites, una de cuyas modalidades típicas es precisamente la "novela familiar" - la expresión es de Freud-, esa interminable escenografía del deșeo imanta cada viraje de la intriga en Puig y, en última instancia, lo escribe. Fascinándolos al mostrarle una aparente incompletud que sólo su imagen podría colmar, una concavidad o un vacio que corresponde a sus siluetas, la fantasía espejea ante los personajes de Boquitas Pintadas y La Traición de Rita Hayworth, cuadro en que al paisaje falta un rectángulo, que viene a ocupar - la invención es de Magritte- un cuadro interior, recién pintado, que representa precisamente el fragmento de paisaje correspondiente al rectángulo.

Pero lo imposible es lograr la coincidencia, el ajuste entre los personajes y sus fantasias, la identificación de los actores con los actuantes: A cada aproximación surge una disonancia; algo sobra, que, de la realidad, resiste a conformarse al andamiaje mítico: caída, suplemento, pérdida. $\mathrm{Y}$ este décrochage tiene lugar aún cuando los lugares comunes son negativos. Ni siquiera el más socorrido de ellos, la tuberculosis, con su discreto histrionismo de toses, pañuelos manchados, sudores y manos amarillentas, logra captar enteramente a los personajes. Aquí, si la enfermedad coincide con su modelo romántico -un catálogo lírico de síntomas repul. sivos, ese rosado empalagoso y sanguinolento que podria ser el de un Watteau-, el héroe no llega a vivirla como tal: Juan Carlos primero la ignora, después finge ignorarla y por último la (de) niega. Pero esta denegación no lo integra tampoco en el lugar común "enfermedad rechazada, antítesis (lugar privilegiado de nuestra retórica) entre corrupción 
y resistencia vital"; acepta el hospital aunque transgrede sus leyes; a cada alarma corresponde una precaución y un disparate, a la crisis la fobia y la fanfarronada.

Sin los lugares comunes que los atraen y escriben, los personajes estarían perdidos, librados a la invención (nula) de sus vidas, a su arbitrio. La solicitud, la urgencia de modelos, de consignas míticas, es tan apremiante, la ausencia de éstos se vive a tal punto como una carencia -la carencia o "falta" (manque) de que hablan los drogados: estos personajes son drogados de lugar comin- que su consumo debe preceder todo diálogo; la conversación, alienada por este vértigo, se ha reducido a una simple "conexión". Después de varios años sin verse, y con una "masa de información" enorme que comunicarse, apenas esbozado un diálogo banal de recepción, Nené y Mabel, amigas intimas y rivales, no atinan más que a escuchar el Radioteatro de la Tarde, folletín "divino" de las cinco. ${ }^{1}$

1 "Aquella fría madrugada de invierno Pierre divisó desde su escondite en lo alto del granero, el fuego cruzado de los primeros disparos. Ambos ejércitos se enfrentaban a pocos kilómetros de la granja. Si tan sólo pudiera acudir en ayuda de los suyos, pensó. Inesperadamente se oyeron ruidos en el granero, Pierre permaneció inmóvil en su cubil de heno.

"-Pierre, soy yo, no temas..."

"-Marie... tan temprano".

"-Pierre, no temas...

- "Mi único temor es el de estar soñando, despertar y no verte más... allí... recostada en el marco de esa puetta, detrás tuyo el aire rosado del alba..."

-Mabel, no me digas que hay algo más hermoso que estar enamorada.

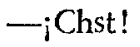

"- Pierre... ¿tienes frío? La campiña está cubierta de un rocío glacial, pero podemos hablar con calma, él ha ido al pueblo".

"- - Por qué tan temprano? ¿Acaso no va siempre a mediodía?

"-Es que teme no poder ir más tarde, si la batalla se extiende. Por eso he venido a cambiarte la venda ahora".

"-Marie, déjame mirarte. Tienes los ojos extraños, ¿acaso has estado llorando?"

"-Qué cosas dices, Pierre. No tengo tiempo para llorar". ${ }^{1}$ 
${ }^{1}$ La función del folletín en primer grado en el interior del folletín en segundo no es sólo la de apaciguar la carencia y sentar las normas fantásticas del relato. Podríamos asignarle otra, a condición de sintetizar bien la LR7 de Buenos Aires, su emisora amiga, y escuchar el desenlace. provisional, claro) del radioteatro:

- Como en el teatro-en-el-teatro de Shakespeare, el folletín interior esquematiza metafóricamente, aunque invirtiéndola, parcialmente, la acción primordial del folletín-continente: en ambas novelas la mujer se ha entregado a "un muchacho joven" que posteriormente resulta lesio. nado (Juan Carlos tuberculoso; Pierre gravemente herido); pero si Juan Carlos es expulsado al exterior -el sanatorio está en Cosquín, lejos de Coronel Vallejos--, Pierre es confinado en el interior - Marie lo esconde y cura en lo alto del granero-; en ambas novelas a la lesión sucede la intervención decisiva de un personaje marginal (la hermana de Juan Carlos/el hermano del "marido bruto") pero en Boquitas Pintadas esta intervención obliga a los amantes a separarse y en la novela de las cinco a unirse; por último, esta inversión (contagio/complicidad) suscita otra: Pierre mata, Juan Carlos muere. Esta función de reducción remite al lector -demasiado célebre artificio borgesco- a su facticidad, a su ser-en-la-ficción; en el caso de Puig también a su ser-en-el-pasado. ${ }^{1} \mathrm{La}$ acción de Boquitas Pintadas ocurre diez años antes de ser contada por sus propios personajes; la de la novela radiofónica veinte años antes que la de la novela que la comprende.

\section{1 "Sentir}

que es un soplo la vida, que veinte años no es nada, que febril la mirada errante en la sombra te busca y te nombra".

Alfredo Le Pera

\section{RITA HAYWORTH VENNTE ANTOS DESPUES}

En 1946, cuando filmó Gilda, que podremos ver el lunes por la noche en la segunda cadena, Rita Hayworth tenía 28 años. Poco antes, en el año de la bomba atómica, los infortunados japoneses que habían recibido esa maldición del cielo se conformaron tanto menos con ella cuanto desconocian un detalle conmovedor: el proyectil llevaba en sus flancos, pin- 
tada en trompe-l'oeil, la silueta de la estrella. Cosa que el desarrollo de su experiencia no les permitió, hélàs, saber jamás.

Desde 1943 Rita era la esposa del joven genio Orson Welles, su segundo marido, y sin embargo, la estrella había tenido una adolescencia claustrada, totalmente dedicada al trabajo.

El primer productor que se había decidido a convocarla la encontró demasiado gorda; de modo que se la entregó a los especialistas en estética de la firma para que la remodelaran según su idea. De trigueña, la hicieron pelirroja. Para ensancharle la frente le arrancaron parcialmente el cuero cabelludo con cera y electricidad. Para cambiarle su cara de múnecona le exigieron que no comiera a ver si lograba ahuecar sus mejillas. Rita salió de sus manos enteramente transformada. Gracias a lo cual obtuvo un papelito de bailarina en El Infierno. [de Dante].

[...] El 17 de octubre, cuatro días después de la transmisión en nuestra televisión de Gilda, Rita festejará sus 51 años. De tiempo en tiempo se le ve en el reparto de algún film, próximamente en La Ruta de Salina, de Georges Lautner. Si bien es cierto que su nombre ya no figura en las grandes letras de antaño, también lo es que Rita comienza a dar pruebas de sus reales cualidades de actriz". ${ }^{1}$

L. S. La Semaine Radio Télé No. 41

₹ El radioteatro de la tarde tendría una tercera función: hacer surgir el modelo en la trama de su doble paródico, el paragrama en medio de la parodia, la fantasía (deshecha la sutura) superpuesta a la realidad, el lugar común en su esplendor, fascinándonos, imantándonos, alienándonos. De allí que Boquitas Pintadas sea también una obra de "contestación", que el gesto que la suscita sea liberador, subversivo.

SEVERO SARDUY

París. 
